
does the hardness after hardening. And up to a content of 0.85 \section{OF THE SURFACE TREATMENT OF THE SELECTED COMPONENT DEPENDING ON ITS SHAPE COMPLEXITY}

EMIL SPISAK, GERHARD MITAL, JAN VARGA, TOMAS JEZNY, IVAN GAJDOS

Technical University of Košice, Faculty of Mechanical Engineering, Department of Mechanical Engineering Technologies and Materials, Kosice, Slovak Republic

DOI: 10.17973/MMSJ.2020_11_2020035

gerhard.mital@tuke.sk

This publication deals with the issue of powder coating for the purpose monitoring the quality of the deposited layer depending on the complexity of the product and the type of material. Describes methods and materials used in different types of deposition of protective coatings. The work is carried out experiment, which expresses quality and thickness applying colour to the diagnosed sample and offering a comparison of the measured values of the samples of the powder coating applied.

KEYWORDS

monitoring, powder coating, paint thickness, corrosion, measuring

\section{INTRODUCTION}

Most metal objects are exposed to oxygen affecting, aggressive gases in the air, water and various chemicals. These external influences act primarily on the metal surface. They change its appearance and often also its mechanical properties and for its purpose it is practically unusable, therefore it is necessary to increase the technical level, quality and reliability of engineering products while respecting economic and environmental limits are among the main directions of economic development [Spisak 2011 \& 2015, Podjuklová 1994]. When using these products, they also interact with the surrounding environment and thus their surface degrades due to wear, corrosion and other influences [Mital' 2016, Valíček 2016]. Surface treatments thus contribute to the final quality of the technical equipment. They affect its service life, running reliability and thus usability, readiness, maintenance requirements. Insufficient or inadequate surface protection can also degrade a technical work [Majernikova 2014, Cacko 2014]. Surface protection affects and conditions not only the functionality of engineering products, but also their appearance [Krenicky 2012 \& 2015, Ružbarský 2018]. Although the visually impaired equipment is still functionally usable, its sales capacity decreases and the possibility of degrading the surrounding environment increases [Spisak 2011].

\section{MATERIALS AND METHODS}

The diagnosed sample (Fig. 2) is made of steel with improved atmospheric corrosion resistance. This steel has similar properties to non-alloy steel, but is more suitable for heat treatment. It is possible to influence the mechanical properties wt. \% C.

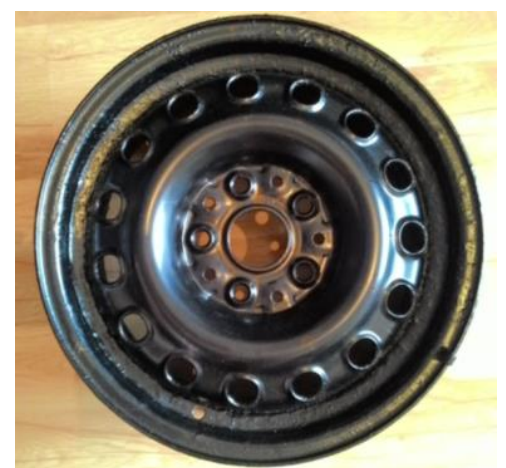

Figure 2. Diagnosed sample of stainless low-alloy steel 15217 (EN 10027-2)

The steel used for the production of the disc was steel of class 15 , i.e. stainless alloy (Tab. 1), steel with improved atmospheric corrosion resistance, intended for further heat treatment and containing manganese, silicium, chromium, vanadium, wolfram, molybdenum.

\begin{tabular}{l|l|}
\begin{tabular}{l} 
Table 1. Steel specification \\
\hline Grade
\end{tabular} & S355J0WP \\
\hline Number & 1.8945 \\
\hline Classification & $\begin{array}{l}\text { steel with improved atmospheric corrosion } \\
\text { resistance }\end{array}$ \\
\hline Standard & $\begin{array}{l}\text { EN 10025-5: 2004 Hot rolled products of } \\
\text { structural steels. Technical delivery } \\
\text { conditions for structural steels with improved } \\
\text { atmospheric corrosion resistance }\end{array}$ \\
\hline
\end{tabular}

Method of deoxidation $\mathrm{FN}=$ rimming steels not permitted. For long products the $\mathrm{P}$ and $\mathrm{S}$ content can be $0.005 \%$ higher. The steels may show a Ni content of max. $0.65 \%$ (Tab. 2).

The max. value for nitrogen does not apply if the chemical composition shows a minimum total Al content of $0.020 \%$ or sufficient other $\mathrm{N}$ binding elements are present. The $\mathrm{N}$ binding elements shall be mentioned in the inspection document.

Table 2. Chemical \% composition of the steel S355J0WP

\begin{tabular}{|l|l|l|l|l|}
$\mathbf{C}$ & $\mathrm{Si}$ & $\mathrm{Mn}$ & $\mathrm{P}$ & $\mathrm{S}$ \\
$\mathrm{max} 0.12$ & $\max 0.75$ & $\max 1$ & $0.06-0.15$ & $\max 0.035$ \\
\hline $\mathrm{Cr}$ & $\mathrm{N}$ & $\mathrm{Cu}$ & & \\
\hline $0.3-1.25$ & $\max 0.009$ & $0.25-0.55$ & & \\
\hline
\end{tabular}

\subsection{Selection of the method of powder lacquer coating}

Using electrostatics, there are two ways to apply the powder: Crown (statics)- Tribo (electrokinetic deposition) In both methods, the powder is placed in a hopper (Fig. 3), where it is fluidized (the powder is mixed with air) and then is forced into a gun by air. The methods differ only in the method of charging the powder particles. The charged air-compressed powder is electrostatically attached to a grounded workpiece [Podjuklová 1994, Grytsenko 2015].

Fluidization facilitates the pumping of the powder and also its progress through the pipeline up to the gun. The air used for fluidisation must be dry, clean, free of grease and oil, otherwise impurities could contaminate the powder and clog the screens and membranes in the hopper o the entire system. In our experiment we chose the tribology method [Podjuklová 1994]. 


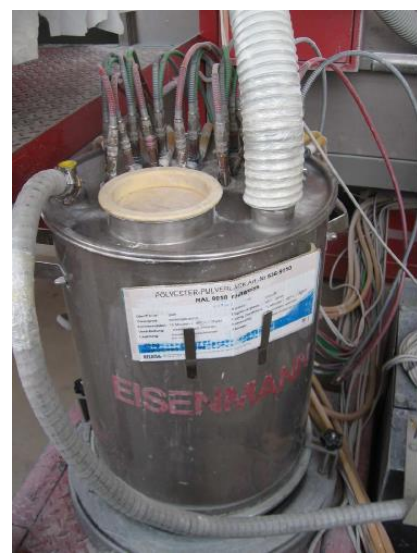

Figure 3. Hopper

\subsection{Method of powder coating - tribo}

The main part of the tribo gun is the outlet tube. The inner layer of the tube is made of a material that absorbs electrons well (e.g. Teflon or PTFE). A mixture of powder and air passes through the gun, electrons are separated from the powder particles by friction against the wall of the tube, and thus the powder acquires a positive charge and at the same time charges the tube with a negative charge. The gun is grounded and the negative charge passes to the ground. The powdered part is also grounded and holds the powder particles (Fig. 4).

Powders for tribo guns must be good electron donors (nylon, epoxy). Larger powder particles are more suitable for more efficient charging.

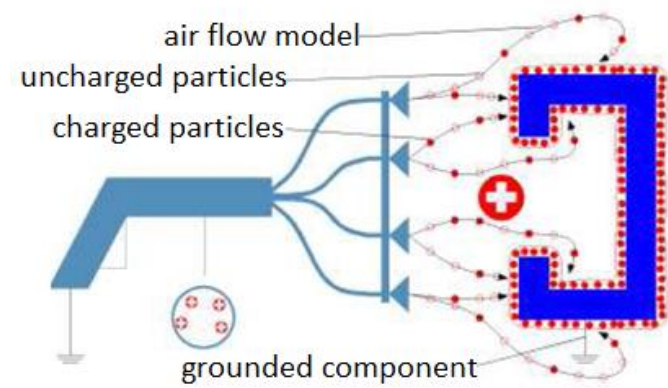

Figure 4. Tribology method

The tribo method does not have such back ionization problems as the crown method, because the same electric field strength cannot be achieved by friction. It is therefore not a problem to apply the powder in several layers [Podjuklová 1994].

The spray gun (Fig. 6) is made by the manufacturer ITW Gema $A G$, Switzerland.

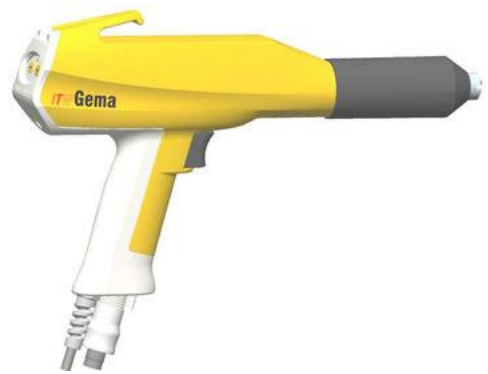

Figure 6. Spray gun used for tribology method

\subsection{Negative events at electrostatic coating}

Faraday cage - is an effect arising from more complex shapes of parts. Electrostatic lines of force are concentrated at the edges rather than at the bends. Also, the flowing air circulates in a bend and carries the powder away. The Faraday space is just in the bend.
Back ionization - is an event that occurs when the thickness of the powder coating layer begins to increase. The force of the electric field between the layers of powder and the surface of the material begins to increase. Positive and negative ions are formed. Positive ions begin to move toward the negatively charged electrode on the gun, firing, causing the powder layer breakings. Small craters are formed, which are called "starring" and also called "orange peel".

\subsection{Firing}

After applying the lacquer, the parts are fed to hardening furnace. Thus, the powder melts by heating and a chemical reaction occurs, resulting in a solid hard layer. The chemical reaction causes the polymers to crosslink, which gives the surface resistance to failure.

In the experiment, a conventional hot air furnace was used for firing (Fig. 5). In a hot air furnace, natural gas is usually used for heating. Heated air is circulated with the help of fans. The temperature in the hardening furnace is in the range of approx. $140-220{ }^{\circ} \mathrm{C}$. The powdered part first reaches the ambient temperature in the furnace and then begins to conduct heat into the powders and causes them to melt. The firing temperature depends on the type of powder. Burning time ranges from 10 to 30 minutes. If the required parameters are not achieved, the lacquer may not have the necessary adhesion, peeling of the material could occur.

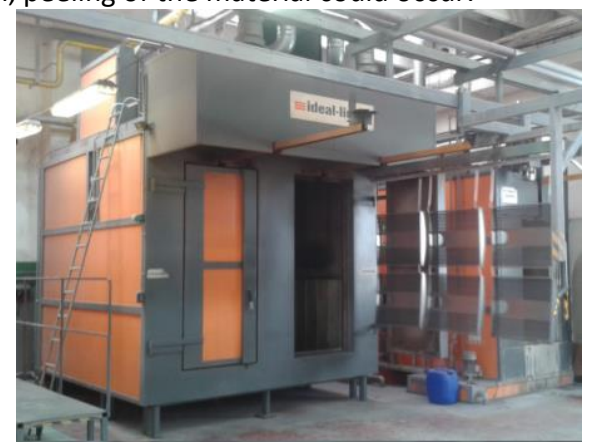

Figure 5. Hot air furnace

After cooling of such treated parts it is possible to send them to mounting or for further expedition. The surface of such heattreated part will not melt and drop even when heating.

\subsection{Description of powder coating material}

Paint designation: Teodur AP ARCHITECTURAL.

Product designation and final tone: RAL 9005 JET BLACK Matt Smooth.

Hardening conditions: $12 \mathrm{~min}$ at $190^{\circ} \mathrm{C}$.

Glance: 30 +- 5.

Product code according to which the final properties of the paint are determined: AE30014900520:

$\mathrm{AE}$ - Chemistry quality - Polyester architectural primid,

3 - glance $/ 60^{\circ}$ - 30-39,

0 - smooth surface,

0 - without effect,

1 - no properties,

4 - colour group is black,

9005 - number of paint

minimum recommended thickness for normal use $-50-60 \mu \mathrm{m}$

(Fig. 7). 


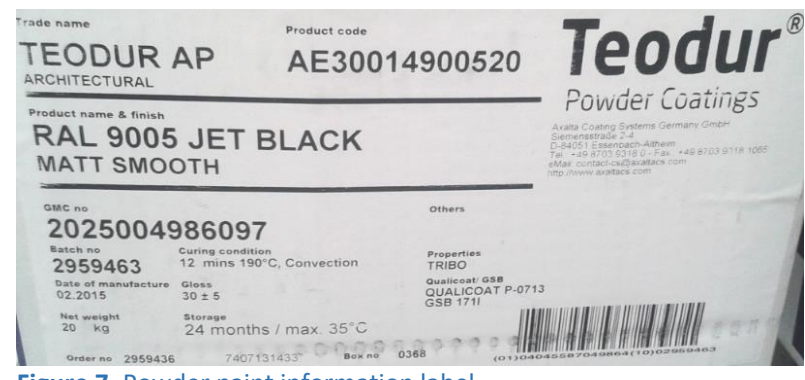

Figure 7. Powder paint information label

\subsection{A device for measuring the applied thickness of lacquer}

The thickness of the treated surface was measured with a PHYNIX Surfix Version F 2.2 Basic unit (Fig. 8), which is made in Germany. This device is the most widespread device for measuring layer thickness. It is ideal for paint shops, electroplating, for production and also for receiving or output inspection.

The device contains a sonde, which is firmly connected to it and is also connected to the data storage, statistical evaluation and infrared port. The measuring sonde is type F 2.2. Calibration is two-stroke. Measuring range: 0 - $1500 \mu \mathrm{m}$.

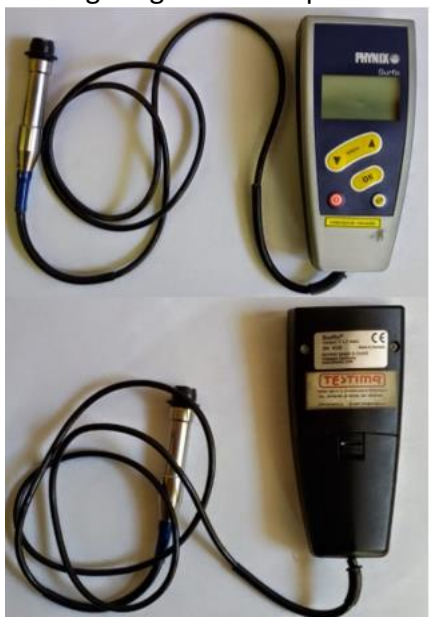

Figure 8. Measuring device PHYNIX with sonde type F 2,2

\section{Measures were intended for:}

- Obtaining a larger number of values in order to improve the profiling of the applied layer thickness.

- Measurement of complex shapes and flat surfaces to evaluate the flow and adhesion of the paint during application.

- Determining the quality of the applied protective layer.

- Monitoring the quality of electrostatic powder coating.

The measurement of the diagnosed object was performed at the Department of Engineering Technologies, Materials and computer aided production (KSTMaPPV) in the premises of the engineering workshop. First of all, it was necessary to determine the measurement points on the diagnosed object. When determining the points, the shape of the sample was taken into account in the first place, and thus the places on the edges of the holes and around the holes at more shapedemanding surfaces were selected. However, the choice of these points also depended on the position of the disc during the application of the protective material itself.

This was followed by the second phase before the measurement itself, namely the calibration of the instrument for measuring the thickness applied.

\section{Calibration procedure:}

1. Press the menu button to search for the calibrate function,

2. Before using the device for measurement, it must first be calibrated by placing the sonde $F 2,2$ on the calibration scale in the marked field and pushing the "ok" button, using a calibration scale (Fig. 9) and calibration foils (Fig. 10).

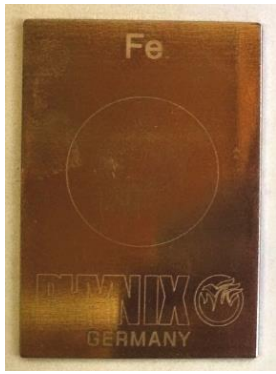

Figure 9. Calibration scale with marked field

3. In the calibration menu, the "scale calibration" function has been set where a calibration foil with a thickness of $103 \mu \mathrm{m}$ has been placed on the calibration scale.

4. Verification of the setting by applying it to the calibration scale, where the device read a certain value, which we adjusted in the calibration menu according to the calibration foil to the value $103 \mu \mathrm{m}$.

6. Replacement of the calibration foil with a foil thickness of $513 \mu \mathrm{m}$ and subsequent repetition of this procedure while monitoring the measured thickness and the prescribed tolerance.

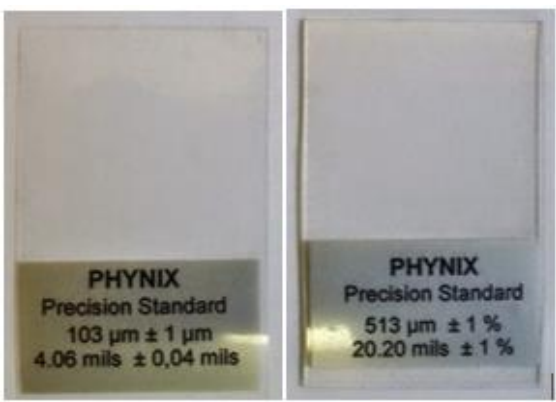

Figure 10. Calibration foil with thickness $103 \mu \mathrm{m}$ to the left a $513 \mu \mathrm{m}$ to the right

\section{MEASURED VALUES}

In the first phase of the process, the steel disc had to be cleaned and degreased. For this three types of rinsing were used, which were performed in the first part of the technological line, namely the pre-surface treatment cabins (Fig. 11).

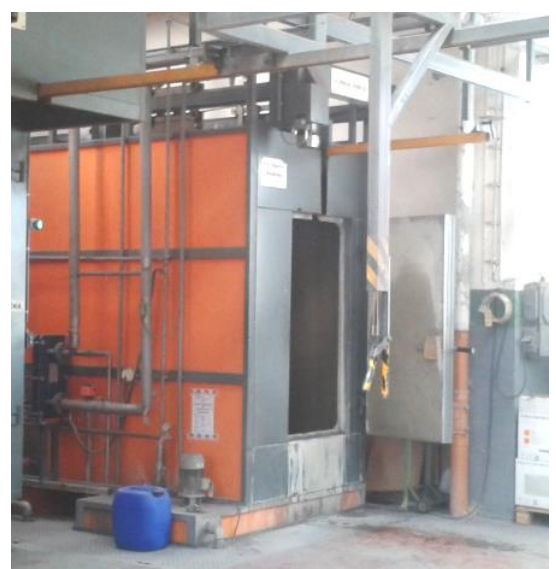

Figure 11. Pre-surface treatment cabin 
The first rinse was performed by ferric phosphating:

- concentration: $10-15 \mathrm{~g} / \mathrm{l}$

- temperature: $30-50{ }^{\circ} \mathrm{C}$

- pressure: $1.0-1.5 \mathrm{bar}$

- $\mathrm{pH}: 4.0-5.0$

- Exposure (drip): $3.0 \mathrm{~min}$

This was followed by a second rinse with domestic water at a pressure of: 1.0-1.5 bar, conductivity: inlet $+400 \mu \mathrm{S}$ and exposure thus dripping for $3.0 \mathrm{~min}$. The last rinse was identical to the second except for the conductivity, which was input+100 $\mu \mathrm{S}$. During the operations in the pre-treatment cabin, the cabin temperature was set at $50^{\circ} \mathrm{C}$.

This was followed by a drying operation when the disc was cleaned and rinsed using the manipulators of the technological line transported to the drying furnace, where it was dried for 10 minutes at a temperature of $180^{\circ} \mathrm{C}$.

First of all, it is necessary to define a value that will serve as a standard for the thickness of the applied paint layer. This value was obtained by the arithmetic mean of the measured values at points that were measured on the flat surfaces of the product because the flat surfaces showed the same layer of applied layer thickness with only small differences. The recommended thickness of the applied layer of paint for common use is given by the material sheet of the product to the value of $50-60 \mu \mathrm{m}$. Since the tested sample is used in non-abrasive conditions where a higher resistance is required, which requires a greater thickness to at least twice the recommended value, so we determined a thickness of $148 \mu \mathrm{m}$ for the reference value, which is the average of the set of measured values.

The first series of measurements was performed on the inside of the disk (Fig. 12 right). 4 measurements were made, 12 points each. The measurements were always performed at the same points on the surface. The measurements were shifted by $90^{\circ}$ relative to each other (Fig. 12 left) and were performed from left to right. The ideal condition would be the same thickness over the entire surface of the part, but due to the shape complexity and the resulting turbulent flow during the application of the protective material, this is not possible. Thus, we assume that the thickness of the coating in places with shape difficulty will decrease significantly at the square ends of the sample and increase in places with the shape of the cavity (corners). Exceptions are curved places or places oriented in horizontal directions in which the flow of the applied material is different than in the case of complex shapes, which is reflected in the uneven thickness of the flowed applied material. Average value of the thickness of the applied lacquer layer: $185.99 \mu \mathrm{m}$.

The Fig. 13 and the averages of the values (Tab. 3, column Average), which were created by averaging the measured values, show that the average measured value at point 1 is $317.15 \mu \mathrm{m}$ and is therefore $114.3 \%$ larger than the standard value and in point 12 the layer thickness is $432 \mu \mathrm{m}$ and thus 191.9\% larger compared to the reference value of the paint thickness, which was caused by the fact that point 1 and point 12 are in places that have the shape of a rim (trap), where more paint was caught. It clearly follows from these two points that the thickness of the applied layer depends on the complexity of the shape of the applied surface, which is also evident from the values recorded graphically. Graph 13 shows the curves of the average of the measured values in black. The measured values should approach this average with a tolerated deviation. Significant changes in thickness were in the mentioned points 1,12 and also in points 5 and 9 which are rounded. The other points are in the tolerated range and also move in the tolerance range from the point of view of the obtained standard value of $148 \mu \mathrm{m}$.

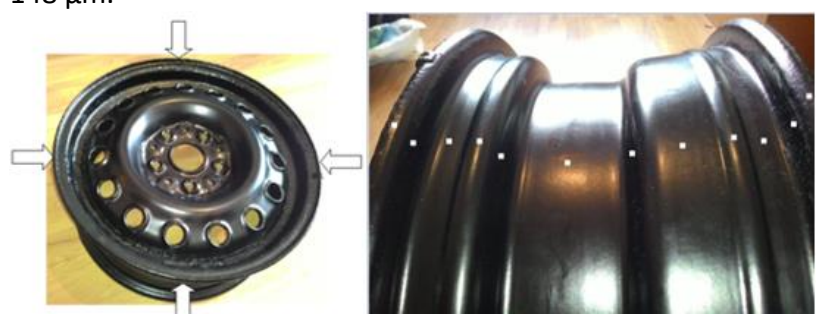

Figure 12. Measurement of inside disc flats

Table 3. Measured values from the first series of measurement

\begin{tabular}{|c|c|c|c|c|c|}
\hline \multirow{2}{*}{$\begin{array}{l}\text { Measure } \\
\text { points }\end{array}$} & \multicolumn{5}{|c|}{ Measurement } \\
\hline & 1 & 2 & 3 & 4 & Average \\
\hline 1 & 324.5 & 269.5 & 245.6 & 429 & 317.15 \\
\hline 2 & 159.8 & 131.6 & 125.4 & 122.4 & 134.8 \\
\hline 3 & 145.8 & 120.8 & 142.2 & 162.2 & 142.75 \\
\hline 4 & 170 & 124.8 & 190.8 & 184.6 & 167.55 \\
\hline 5 & 164.6 & 133.2 & 211.4 & 243.2 & 188.1 \\
\hline 6 & 169.2 & 115.8 & 172.6 & 165.4 & 155.75 \\
\hline 7 & 150.8 & 85.3 & 174.2 & 181.6 & 147.975 \\
\hline 8 & 118.2 & 103 & 138.4 & 138.2 & 124.45 \\
\hline 9 & 118 & 83.3 & 184.6 & 172.6 & 139.625 \\
\hline 10 & 153 & 151.8 & 114 & 123.2 & 135.5 \\
\hline 11 & 150.8 & 145.6 & 161.6 & 127 & 146.25 \\
\hline 12 & 472 & 351.5 & 534 & 370.5 & 432 \\
\hline
\end{tabular}

The second series of measurements was performed at the places of the front side of the disk (Fig. 15) where there is a greater shape complexity.

The graph (Fig. 14) and the averages of the values (Tab. 4; column Average), which were created by averaging the measured values, shows that the measuring places of points (right to left)1 (hemispherical shape), 2 (narrow flat surface following the hem of point 1 and the arched shape of point 3 ), 3 (semi-arc shape), 4 (inner arc shape) from the graph (Fig. 14) it follows that these points are in places of complex shapes. These complex shapes caused large deviations of the measured values. In the case of point 1 with a layer thickness of 400.8, this is a difference of $170.8 \%$, and in the case of point 2 with a thickness of 400.9 , this is a difference of $170.9 \%$ of the required thickness value. In point 3, which has a value of $499.25 \mu \mathrm{m}$, the measured layer thickness is increased by $237.3 \%$ and in point 4 , the measured thickness of the lacquer layer is increased by $242.7 \%$. 


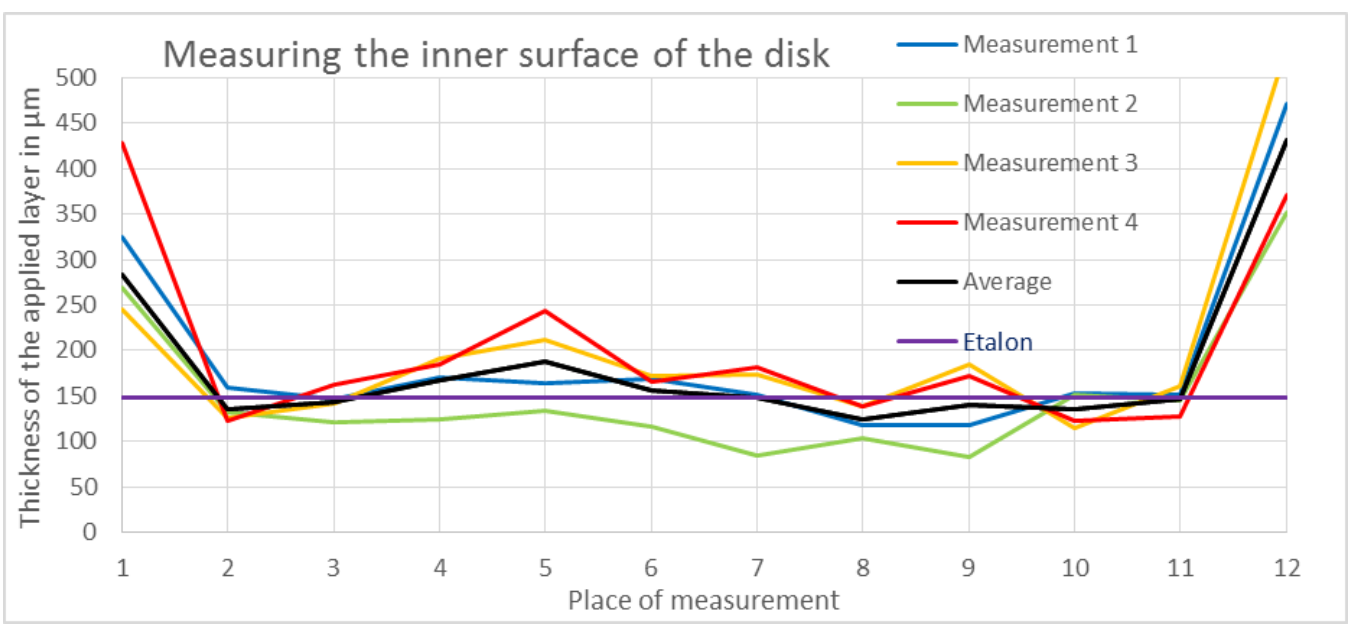

Figure 13. Graph of measured values of internal surfaces of the disk from four sides

Table 4. Measured values of the first series of measurements

\begin{tabular}{|l|l|l|l|l|l|l|l|l|l|}
$\begin{array}{l}\text { Measure } \\
\text { points }\end{array}$ & \multicolumn{9}{|c|}{ Measurement } \\
\hline & $\mathbf{1}$ & $\mathbf{2}$ & $\mathbf{3}$ & $\mathbf{4}$ & $\mathbf{5}$ & $\mathbf{6}$ & $\mathbf{7}$ & $\mathbf{8}$ & Average \\
\hline $\mathbf{1}$ & 295 & 251.5 & 284 & 283.5 & 271 & 387 & 353.5 & 381 & 331.3 \\
\hline $\mathbf{2}$ & 382 & 484.5 & 289.5 & 232.6 & 292.5 & 443.5 & 295.5 & 287 & 338.4 \\
\hline $\mathbf{3}$ & 259 & 283 & 276 & 258.5 & 376.5 & 235 & 235 & 271 & 274.25 \\
\hline $\mathbf{4}$ & 716.8 & 605 & 775 & 818 & 601 & 752 & 771 & 819.5 & 732.3 \\
\hline $\mathbf{5}$ & 150 & 252 & 155.6 & 163.2 & 151.2 & 147.4 & 226.6 & 117.4 & 170.4 \\
\hline $\mathbf{6}$ & 139.8 & 189.6 & 172.8 & 164 & 149.6 & 170 & 170 & 148.6 & 163.1 \\
\hline & & & & & & & & & \\
\hline
\end{tabular}

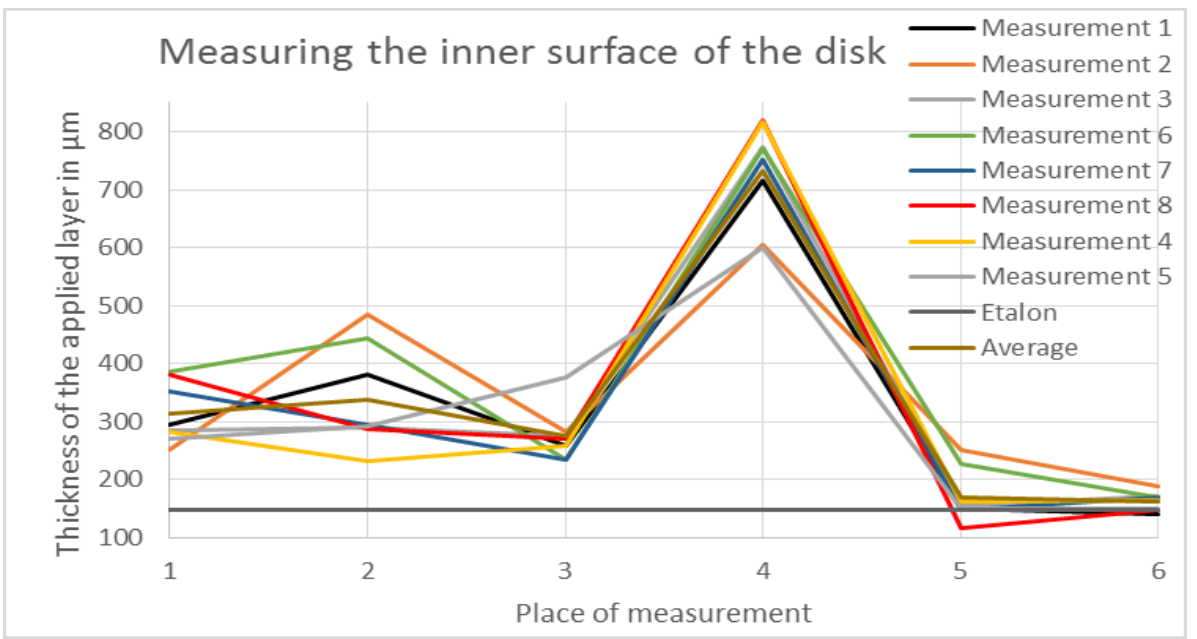

Figure 14. Graph of measured values of internal surfaces of the disk from four sides

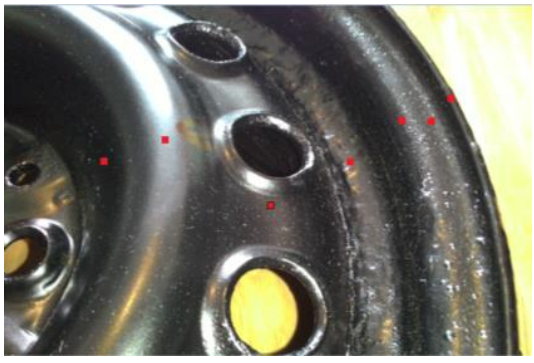

Figure 15. Front side of the disk

At point 5 with a value of $171.5 \mu \mathrm{m}$, which was measured on a flat surface, the measured layer thickness was $14.8 \%$ more, and at point 6 with a thickness of $163.1 \mu \mathrm{m}$, which is also measured on a flat surface, the measured layer thickness was $10,2 \%$ more. Both of these points have a planar character and in tolerance up to $+10 \%$ to $-10 \%$ which is +14.8 to $-14.8 \mu \mathrm{m}$ of the value of the applied layer thickness. The essence, however, remains the fact that flatness and relative shape simplicity are a good factor for achieving the desired thickness of the applied layer of paint, while at points 1,2, 3, 4, which are located at the complex shapes of the disk, the thickness is largely outside the tolerance limits of average and reference value.

\section{DISCUSSION}

The aim of this study was to evaluate the thickness of the applied layer of powder coating on a complex component. The experiment took place at the Department of Technology, Materials and Computer Aided Manufacturing Support at the Faculty of Mechanical Engineering in Košice. The sample was made of steel grade $15, \mathrm{t}$. j. stainless alloy with increased resistance to atmospheric corrosion, as the material will be exposed to severe weathering during its function. The measured data were to some extent influenced by the worker 
himself, who performed the application, but this fact proved to be negligible during the experiment.

The thickness of the applied layer was measured at 12 points of the sample (Graph 13) from the inside of the sample in four levels with an offset of $90^{\circ}$ and at six points from the front in eight levels. The average values of individual measurements were created from the measured values. The measured values of the thickness of the sample lacquer layer are given in Table 3 and Table 4. The influence of the complex shape of the product on the thickness of the applied layer is most visible on the graphical representations and measured values of thicknesses at the following points:

The first series, where the layer thickness at individual points required a thickness value of $148 \mu \mathrm{m}$, but the differences in thicknesses at the measured points compared to the reference value were: Point $1-169.15 \mu \mathrm{m}$; point $4-19.55 \mu \mathrm{m}$; point 5 $40.1 \mu \mathrm{m}$; point $8--23.55 \mu \mathrm{m}$; point $12-284 \mu \mathrm{m}$. The biggest problem in this series of measurements is points 1 and 12 because they do not meet the requirement for the recommended thickness of the applied layer of paint used, which is recommended by the manufacturer for normal conditions of $50-60 \mu \mathrm{m}$. It is therefore likely that this unsatisfactory part of the thickness of the paint will not be able to withstand the weather for a long time, as it may peel, crack the material and reduce the ability to protect the engineering product. The reason for this is that it is the edge of the sample where a larger amount of material has accumulated in the air from both sides of the application due to the flow of aerosol. The possibility of removing this thick layer along the edges of the sample is that the worker makes this part of the surface last, where when applying the first layer from one side he omits this part, which would reduce the thickness of the edge layer of paint.

The second series, where the layer thickness at individual points required a thickness value of $148 \mu \mathrm{m}$, but the differences in thicknesses at the measured points compared to the reference value were: Point $1-331.3 \mu \mathrm{m}$; point 2 - $338.4 \mu \mathrm{m}$; point $3-274.25 \mu \mathrm{m}$; point $4-732.3 \mu \mathrm{m}$, where these points significantly exceed the recommended value. It is a rugged part of the surface at the edges and depressions. From the comparison of these values, it is evident that in the parts with a larger depression there is a greater thickness of the applied layer than on the surface protrusions.

\section{CONCLUSION}

One of the modern production methods of surface treatment is the technology of creating coatings from powder coating materials. Powder paints became more widely known in the early 1950 s after the discovery of the solid bottom fluidization process. This method was used to process thermosetting powder paints, and in May 1953, the German scientist Dr. Erwin Gemmer patented it. The commercial use of powder coating is still expanding and already in the middle of the 60s the European annual production of these materials was about 20 tons [Gajdoš 2015].

Advantages of powder coating: Environmentally friendly technology, $100 \%$ solid form of paint, technology that does not use solvents and various other chemicals, thanks to recycling almost waste-free use of powder, economic aspect pushes powder manufacturers to reduce firing temperatures and time required for powder firing process, resulting properties surfaces such as strength, resistance to temperatures, chemicals and other specific properties of special powders, automatic processing is simple and has low application costs, the safety of the whole process is very high and the risk of fire is low.

The thickness of the applied protective layer is one of the properties that affects the service life and reliability of components, energy loss, corrosion resistance, tribological properties, etc. According to the specifications of the standard STN 673051 and STN 67 3061, we measured the thickness of the applied layer of paint, while at individual points of the rugged surface we monitored how the applied paint layered resp. stored or accumulated. As we found in this practical measurement, the surface fragmentation has an effect on the applied layer thickness. The surface of the sample used must be divided and then observed from three categories. The first category is the largest surface depressions where the largest thickness of the applied layer of paint was deposited, while the paint tends to deposit and layer in the given places, while we recorded an increase in the thickness of the varnish three to four times compared to the reference value.

The second category is the edges and roundings of the surface, where in some cases the applied mass has accumulated twice compared to the reference value. The last category that met the requirement for the applied thickness of the coating layer were planar surfaces, where the differences in the thickness of the applied layer ranged from $0-10 \mu \mathrm{m}$. The disadvantage of applying paint was the human factor, which could cause differences in the thickness of the applied layer in certain places (non-observed angle and distance of the gun from the article). This process could be optimized by automating spraying with a spray robot that can work more accurately, especially in terms of maintaining a constant distance and angle of the spray gun head from the material, application speed and also application uniformity.

\section{ACKNOWLEDGEMENTS}

This paper has been supported within the grant VEGA $1 / 0384 / 20$

\section{REFERENCES}

[Cacko 2014] Cacko, P., Krenicky, T., Dobransky, J. Impact of an Excessive Wear of Bearing on the Mechatronic Devices. Applied Mechanics and Materials, 2014, Vol. 460, pp. 99-106.

[Gajdoš 2015] Gajdoš, I. et al. Surface finish techniques for FDM parts. Materials Science Forum, 2015, Vol. 818, pp. 45-48.

[Grytsenko 2015] Grytsenko, O., Spišák, E., Dulebová, L'., Moravskii, V., Suberlyak, O. Sorption Capable Film Coatings with Variable Conductivity. Materials Science Forum, 2015, Vol. 818, pp. 97-100.

[Krenicky 2012] Krenicky, T. Automated noncontact system for characterization of surface geometry. In: Automation and control in theory and practice ARTEP 2012. Feb. 22-24, 2012, Stara Lesna, Slovakia. Kosice: TUKE, 2012. pp. 38-1-38-5. ISBN 978-80-553-0835-7.

[Krenicky 2015] Krenicky, T. Non-contact study of surfaces created using the AWJ technology. Manufacturing Technology, 2015, Vol. 15, No. 1, pp. 61-64. ISSN 1213-2489

[Majernikova 2014] Majernikova, J., Spisak, E. Punch-Die Gap Effect on Blanked Edge in Fine Blanking of Low-Carbon, MicroAlloyed and High-Strength Steels. Applied Mechanics and Materials, 2014, Vol. 474, pp. 279-284.

[Mital' 2016] Mital', G., Dobransky, J., Ružbarsky, J., Olejarova, S. Application of Laser Profilometry to Evaluation of the Surface of the Workpiece Machined by Abrasive Waterjet Technology. Applied Sciences, 2019, Vol. 9, No. 10, p. 2134. 
[Podjuklová 1994] Podjuklová, J. Special technologies of surface treatment I. 1st ed., Ostrava: Publishing centre VŠB Ostrava, 1994, 76 p. ISBN 80-7078-235-8.

[Ružbarský 2018] Ružbarský, J., Mital', G. Diagnostics of selected surface characteristics with laser profilometry. MM Science Journal, 2018, No. March, pp. 2140-2143.

[Spisak 2015] Spisak, E., Dzupon, M., Majernikova, J., Spišáková Dul'ová, E. Failure of Coatings of Tinplates. Acta Metallurgica Slovaca, 2015, Vol. 21, No. 3, pp. 213-219

\section{CONTACTS}

Ing. Gerhard Mital', PhD., Ing. Tomáš Jezný, PhD.

Technical University of Kosice,

Faculty of Mechanical Engineering,

Department of Mechanical Engineering Technologies and Materials,

Mäsiarska 74, Kosice, 040 01, Slovakia
[Spisak 2011] Spisak, E., Slota, J., Majernikova, J. The Analysis of Plastic Strain of Single and Double Reduced Tinplates. Chemical Letters, 2011, Vol. 105, pp. 485-487.

[Valíček 2016] Valíček, J. et al. Mechanism of Creating the Topography of an Abrasive Water Jet Cut Surface. Advanced Structured Materials, 2016, Vol. 61, pp. 111-120. 